\title{
Morphological and molecular classification of genus Anguilla
}

\author{
Jae-Ho Hwang, Kyeong-Ho Han, Seon-Jae Kim, Sung-Ju Rha, Sung-Hoon Lee* \\ College of Fisheries \& Ocean Sciences, Chonnam National University, Yosu 550-749, Korea
}

\section{Email address:}

hwangjh73@yahoo.co.kr (J. H. Hwang), aqua05@chonnam.ac.kr (K. H. Han), foodkims@chonnam.ac.kr (S. J. Kim), rhasj93@naver.com (S. J. Rha), formalin100@hanmail.net (S. H. Lee)

\section{To cite this article:}

Jae-Ho Hwang, Kyeong-Ho Han, Seon-Jae Kim, Sung-Ju Rha, Sung-Hoon Lee. Morphological and Molecular Classification of Genus Anguilla. American Journal of Life Sciences. Special Issue: Marine Biology. Vol. 3, No. 1-1, 2015, pp. 6-9. doi: 10.11648/j.ajls.s.2015030101.12

\begin{abstract}
To establish species-specific systematics to avoid confusing identification of four main commercial species of genus Anguilla in Korea, the relevant species were classified by morphological and molecular methodologies, using body measurement, random amplified polymorphic DNA, and mitochondrial 16S and 12S rDNA determination. Four species of the genus Anguilla from the Far-East (Anguilla japonica), Europe (A. anguilla), America (A. rostrata), and Indonesia (A. bicolor bicolor) were morphologically and genetically distinct from one another.
\end{abstract}

Keywords: Morphology, Systematics, Mtdna, Eel, RAPD, Phylogenetic Tree, 16S and 12S Ribosomal DNA

\section{Introduction}

Eels encompass 15 species and three subspecies, and are widely distributed globally [1]. In Korea, there are four main commercial species, which originate from the Far-East (Anguilla japonica), Europe (A. anguilla), America ( $A$. rostrata), and Indonesia ( $A$. bicolor bicolor). These eels grow in fresh water and breed far offshore after a migration of thousands of kilometers from their freshwater and estuarine habitats to their oceanic spawning areas. The details of these spawning migrations remain unclear. However, the spawning area of the Far-Eastern eel is thought to be located near the seamounts west of the Mariana Islands. Evidence for this supposition lies in the genetic analysis of juveniles of this species, which identified them as A. japonica [2].

Yamamoto and Yamauchi [3] were the first to succeed in the artificial breeding of these eels. The relevant seedling technology has yet to be established. Currently, most Korean domestic juvenile eels are caught in a Korean estuary annually from February to May. The domestic biomass of these harvests has been reduced with river pollution and climate change. Korean fishermen have alternatively relied on imported juveniles from Europe, America, and Indonesia, as well as neighboring Asian countries. These different juveniles are difficult to identify before maturity, at which time the eels begin to express distinguishing morphological characteristics. Moreover, most imported juveniles are quite vulnerable to death due to inappropriate rearing environments; water temperature, high breeding density, and the replacement of breeding water into fresh water are all environmental stresses that can kill the animals if applied incorrectly. No reports have been published containing combined systematic data regarding the morphological and molecular classifications of genus Anguilla in Korea. The present paper describes systematics on the basis of morphological and molecular identification using four different geographic origins to provide fundamental data for effective classification.

\section{Materials and Methods}

Three types of adult eels from the Far-East ( $A$. japonica), Europe (A. anguilla), and America (A. rostrata) as well as one juvenile eel from Indonesia (A. bicolor bicolor) were purchased from a local dealer in Young Kwang-gun, Chonnam, Korea.

The adult eels (approximately $10 \mathrm{~kg}$ ) were packed with oxygen and transferred to the ichthyology laboratory at Chonnam University. Certain individual specimens (approximately $160 \mathrm{~g}$ per individual) were selected for body measurement following $24 \mathrm{~h}$ of culture in the lab to allow depletion of any remaining feed and waste in the organ. The selected eels were anesthetized with ice and subjected to 
exterior body measurements including eye diameter, head length, predorsal length, preanal length, and total length (Fig. 1). These measurements have previously been used for eel classification [4]. The eels were boiled in hot water and the vertebrae were collected and counted from the first vertebra to the caudal vertebra.

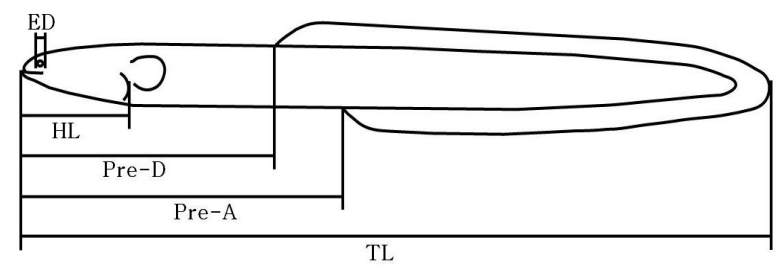

Figure 1. Diagram showing body measurements. Abbreviations are ED: eye diameter, HL: head length, Pre-D: predorsal length, Pre-A: preanal length, and TL: total length.

All mean values were analyzed via one-way analysis of variance (ANOVA). When differences were found among data, Duncan's multiple range test was used to compare the mean difference by using the SPSS software package version 17 (SPSS, USA). Differences were considered significant at $\mathrm{p}<$ 0.05 .

Small pieces $(25 \mathrm{mg})$ of the tail fin from the eels were cut and digested overnight with $20 \mu \mathrm{l}$ of proteinase $\mathrm{K}(600$ $\mathrm{mAU} / \mathrm{ml}$ ) at $56{ }^{\circ} \mathrm{C}$. DNA was isolated using a DNeasy Blood and Tissue Kit (Qiagen, USA). Isolated DNA was maintained at $-20{ }^{\circ} \mathrm{C}$ until use.

PCR amplification was conducted with a $0.4 \mu \mathrm{M}$ primer set based on the mitochondrial 16S ribosomal DNA (16S rDNA) region; 5'-CGCCTGTTTATCAAAAACAT-3' and 5'-CCGG TCTGAACTCAGATCACGT-3', and 12S rDNA region; 5'-T CAAACTGGGATTAGATACCCCACTAT-3' and 5'-TCACT GCAGAGGCTGACGGGCGGTGTGT-3' [5]. PCR was conducted with the G-Taq kit (Cosmo Genetech, Korea). The conditions were initial denaturation for 1 cycle of $95^{\circ} \mathrm{C}$ for 10 min, 35 PCR cycles (denaturating, $95^{\circ} \mathrm{C}, 20 \mathrm{~s}$, annealing, $50{ }^{\circ} \mathrm{C}, 40 \mathrm{~s}$, extension, $72{ }^{\circ} \mathrm{C}, 1 \mathrm{~min}$ ), and a final extension for 1 cycle at $72{ }^{\circ} \mathrm{C}$ for $5 \mathrm{~min}$. Amplified fragments of the expected size were confirmed using ethidium bromide-stained agarose gels $(1.5 \%)$.

A single band (about $600 \mathrm{bp}$ ) was purified using a Wizard SV Gel and PCR Clean-Up System (Promega, USA) and the PCR fragments were subjected to direct sequencing in both directions using ABI PRISM Dye Terminator Cycle Sequencing Ready Reaction Kits (Perkin-Elmer, USA). The $16 \mathrm{~S}$ and $12 \mathrm{~S}$ rDNA nucleotide sequences were aligned and analyzed via CLUSTAL W.

The DNA was subjected to random amplified polymorphic DNA (RAPD). PCR amplification was conducted with $0.5 \mu \mathrm{M}$ of the URP4 primer, 5'- AGGACTCGATAACA GGCTCC-3' [6]. PCR was conducted with the G-Taq kit (Cosmo Genetech). The conditions used were initial denaturation for 1 cycle of $94{ }^{\circ} \mathrm{C}$ for $3 \mathrm{~min}, 35 \mathrm{PCR}$ cycles (denaturating, $94{ }^{\circ} \mathrm{C}, 1 \mathrm{~min}$, annealing, $58{ }^{\circ} \mathrm{C}, 1 \mathrm{~min}$, extension, $72{ }^{\circ} \mathrm{C}, 2 \mathrm{~min}$ ), and final extension for 1 cycle at $72{ }^{\circ} \mathrm{C}$ for $7 \mathrm{~min}$. The amplified fragments showing the expected size were confirmed using ethidium bromide-stained agarose gel (1.5\%).

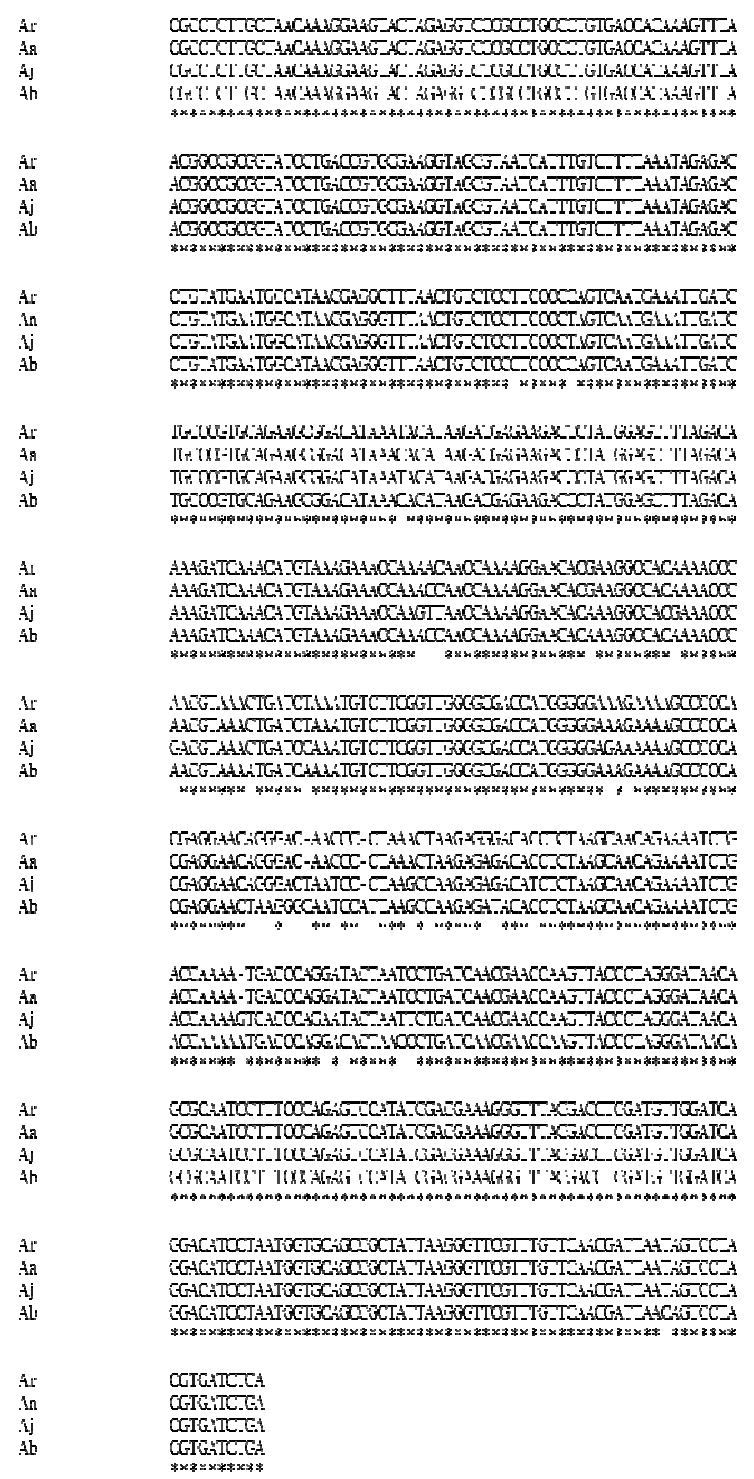

Figure 2. Nucleotide sequence alignment of mitochondrial 165 ribosomal DNA from four species of genus Anguilla. The dashed lines indicate gaps inserted to give the best alignment. Asterisks symbolize fully conserved nucleotide sequences. The NCBI accession numbers of the nucleotide sequence are FJ603300 for Ar (Anguilla rostrata), FJ603301 for Aa (A. anguilla), FJ603302 for Ab (A. bicolor bicolor), and FJ603299 for Aj (A. japonica).

\section{Results}

Table 1. Comparison of head length, predosal length, preanal length, eye diameter, and vertebral column in species of genera Anguilla.

\begin{tabular}{llll}
\hline \multirow{2}{*}{ Characters } & \multicolumn{1}{l}{ Species } & & \\
\cline { 2 - 4 } & A. anguilla & A. japonica & A. rostrata \\
\hline In hundredths of standard length & & & \\
Head length & $12.1 \pm 0.5^{\mathrm{a}}$ & $10.9 \pm 0.6^{\mathrm{b}}$ & $12.7 \pm 0.4^{\mathrm{a}}$ \\
Predorsal length & $29.8 \pm 1.3^{\mathrm{a}}$ & $30.4 \pm 0.8^{\mathrm{a}}$ & $35.2 \pm 1.7^{\mathrm{b}}$ \\
Preanal length & $42.9 \pm 1.2^{\mathrm{a}}$ & $39.8 \pm 0.8^{\mathrm{b}}$ & $43.2 \pm 1.4^{\mathrm{a}}$ \\
In hundredths of head length & & & \\
Eye diameter & $10.1 \pm 0.9^{\mathrm{a}}$ & $8.5 \pm 1.6^{\mathrm{a}}$ & $15.3 \pm 2.7^{\mathrm{b}}$ \\
Number of vertebra & $113.3 \pm 1.2^{\mathrm{a}}$ & $114.3 \pm 1.5^{\mathrm{a}}$ & $108.2 \pm 1.3^{\mathrm{b}}$ \\
\hline
\end{tabular}




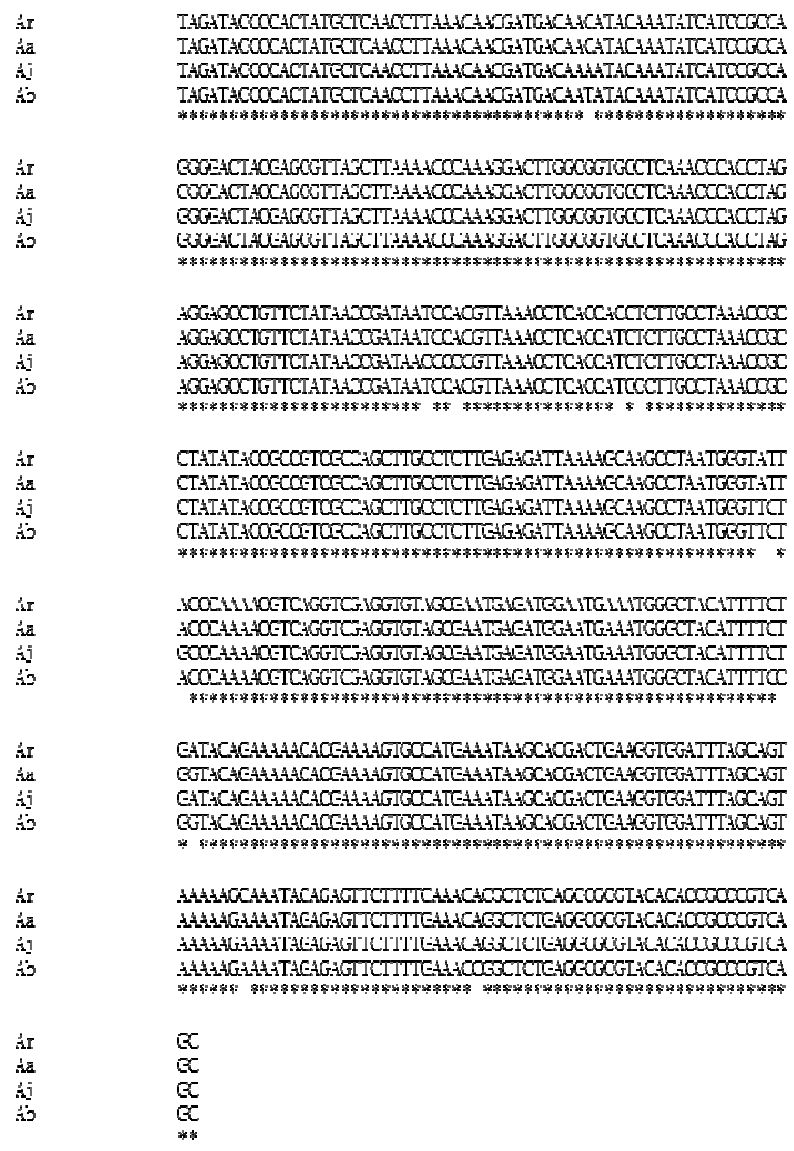

Figure 3. Nucleotide sequence alignment of mitochondrial $12 S$ ribosomal DNA from four species of genus Anguilla. The dashed lines and asterisks are the same as in Fig. 2. Ar, Aa, Ab, and Aj are the same as in Fig. 2, and the NCBI accession numbers of the nucleotide sequence are FJ612584, FJ612585, FJ612586, and FJ612587, respectively.

Far-Eastern eels had smaller eyes than the European and American counterparts. The tail fin and mouth of the Far-Eastern eel was sharp at the end, but those of the European and American counterparts had a round shape. Morphologically, there were some differences between the Far-Eastern eels and European and American eels. European and American eels looked similar.

The average total length of the European, Far-Eastern, and American eels was $439.3 \pm 10.95 \mathrm{~mm}, 450.1 \pm 8.77 \mathrm{~mm}$, and $410.6 \pm 21.82 \mathrm{~mm}$, respectively. The Far-Eastern eel was the longest, followed in order by the European and American eels. With regard to the percentage of head length against total length (Table 1), the European eel was $11.7 \sim 12.8 \%$ (12.1\% on average), the Far-Eastern eel was $10.2 \sim 11.8 \%(10.9 \%$ on average), and the American eel was $12.1 \sim 13.1 \%$ (12.7\% on average). The percentage of head length against total length for the Far-Eastern eel was significantly lower than those of the European and American counterparts. Concerning the percentage of predorsal length against total length (Table 1), European eel $28.5 \sim 31.0 \%$ (29.8\% on average), Far-Eastern eel $29.5 \sim 31.6 \%$ (30.4\% on average), and the American eel $32.5 \sim 36.8 \%$ (35.2\% on average). American eels displayed a significantly long predorsal length that was distinctive from European and Far-Eastern eels. Concerning the percentage of preanal length against total length, European eels were $41.6 \sim 44.7 \%(42.9 \%$ on average $)$, Far-Eastern eels were $38.8 \sim 40.5 \%$ (39.8\% on average), and American eels were $41.9 \sim 45.6 \%(43.2 \%$ on average $)$. The percentage for Far-Eastern eels was significantly lower than those of European and American eels. The percentage of eye diameter against head length (Table 1) was $8.8 \sim 11.0 \%$ (10.1\% on average) for European eels, $6.9 \sim 10.9 \%$ ( $8.5 \%$ on average) for Far-Eastern eels, and $11.2 \sim 18.5 \%$ (15.3\% on average) for American eels. The latter was significantly greater than for European and Far-Eastern eels.
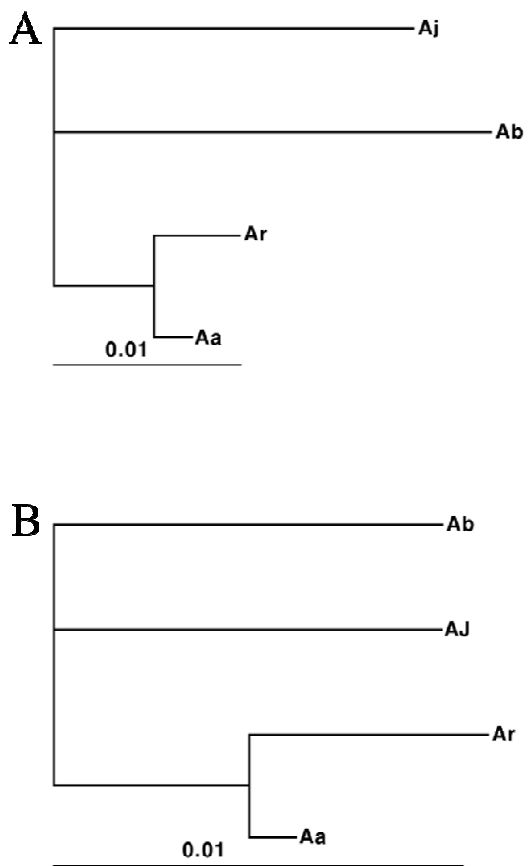

Figure 4. Phylogenetic tree based on nucleotide sequences of mitochondrial $16 S(A)$ and $12 S(B)$ ribosomal DNA from four species of genus Anguilla. The scale bar shows substitution of one nucleotide sequences per 10 nucleotide sequences. Phylogenetic tree was constructed by joining nucleotide sequences of four species of genus Anguilla. Ar, Aa, Ab, and Aj are the same as in Fig. 2.

European eel had 111 115 vertebrae (113.3 on average), Far-Eastern eels had 112 116 (114.3 on average), and American eels had 106 110 (108.2 on average). The number of vertebrae for American eels was significantly smaller than for European and Far-Eastern eels; between the latter, the number of vertebrae was not a distinguishing feature (Table 1).

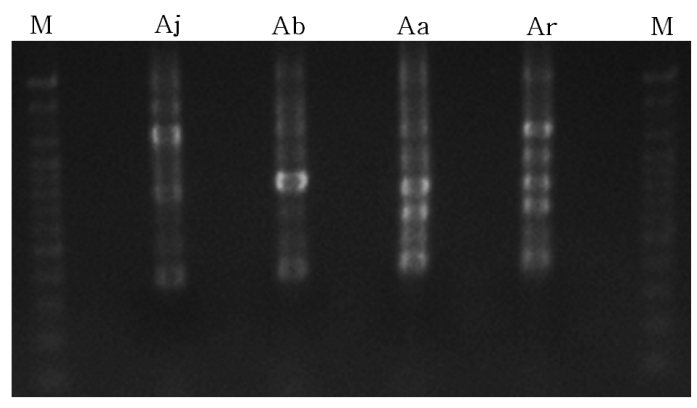

Figure 5. PCR fingerprints of four species of genus Anguilla amplified by primer URP4. Lane M, 100bp ladder; lanes Aj, Ab, Aa, and Ar are the same as in Fig. 2. 
Nucleotide sequences of 16S rDNA on four species in the genus Anguilla are provided in Fig. 2. The result was an alignment of PCR amplification products (approximately 540 $\mathrm{bp}$ ). With regard to the composition of nucleotide sequences, all four species evidenced slightly higher ratios of the $\mathrm{G}+\mathrm{C}$ pair (Far-East, 53.9\%; America, 53.5\%; Europe, 53.5\%; Indonesia, 53.6\%) as compared to the $\mathrm{A}+\mathrm{T}$ pair (Far-East, 46.1\%; America, 46.5\%; Europe, 46.5\%; Indonesia, 46.4\%). However, the $12 \mathrm{~S}$ rDNA nucleotide sequences (about 420bp) on the four species of genus Anguilla (Fig. 3) evidenced an opposite composition with a slightly higher ratio of the A+T pair (Far-East, 53.3\%; America, 53.5\%; Europe, 53.8\%; Indonesia, 53.1\%) as compared to the $\mathrm{G}+\mathrm{C}$ pair (Far-East, 46.7\%; America, 46.5\%; Europe, 46.2\%; Indonesia, 46.9\%). The phylogenetic tree based on the $16 \mathrm{~S}$ and $12 \mathrm{~S}$ rDNA nucleotide sequences showed that closer geographical location influenced the tree (Fig. 4). RAPD amplified by the URP 4 primer is shown in Fig. 5. Species-specific patterns were observed at $1100 \mathrm{bp}, 900 \mathrm{bp}, 700 \mathrm{bp}$, and $1000 \mathrm{bp}$ for the Far-Eastern, Indonesian, European, and American eels, respectively.

\section{Discussion}

Juvenile eels captured in seawater are transferred to an eel farm, and the culture water is gradually replaced by fresh water over a period of 4-5 days. Simultaneously, the rearing water temperature is increased slowly, by $3{ }^{\circ} \mathrm{C}$ per day. Experienced Korean farmers say that the optimum rearing temperature is $28-30{ }^{\circ} \mathrm{C}$ for the Far-Eastern eel; while imported juvenile eels are generally reared at a lower temperature $\left(24{ }^{\circ} \mathrm{C}\right)$. The optimal growth temperature is different depending on the species and developmental stage; $28.33{ }^{\circ} \mathrm{C}$ for the American eel [7], 24 26 ${ }^{\circ} \mathrm{C}$ for Japanese eel embryos, and $26 \sim 28{ }^{\circ} \mathrm{C}$ for the yolk-sac larvae [8]. These different rearing temperatures can cause massive die-off, unless farmers are cognizant of the origins of the juvenile eels prior to the initiation of the culture process. Farmers can suffer economic loss and associated stress this lack of knowledge; sudden death of all the juvenile eels in a culture can occur. In such cases, the farmers often suspect that the juvenile eels they purchased were imported eels rather than domestic eels, since domestic eels in Korea (primarily the Far-Eastern eel) have a higher consumer preference, and thus a higher price, than the other species.

The establishment of a concise classification system for differentiation between domestic and imported eels is crucial to the Korean eel market. However, imported juvenile eels, which are routed principally from Hong Kong, are difficult to track in terms of origin, and can only be distinguished from domestic eels by morphological characteristics that are expressed in maturity. Therefore, the current study sought to establish a species-specific classification on the basis of morphological characteristics and molecular genetic traits. The relevant species were classified by using body measurement, RAPD, and phylogenetic tree based on the mitochondrial $16 \mathrm{~S}$ and $12 \mathrm{~S}$ rDNA determination.

The present results should prove useful in reducing the effort and time necessary for species identification, and should also ensure a higher degree of classification accuracy than has previously been possible. Moreover, the application of DNA analysis for the identification of the juvenile eels should prove useful to several other fields of inquiry: resource management of coastal fishes, fundamental research for understanding long-term changes in fishes, distribution of fish, and resource changes [9, 10]. Further research is necessary to develop a DNA chip capable of user-friendly rapid diagnosis for industrial applications.

\section{Acknowledgements}

This research was supported by Basic Science Research Program through the National Research Foundation of Korea (NRF) funded by the Ministry of Education, Science and Technology (2011-0011204).

\section{References}

[1] J. Aoyama, M. Nishida, and K. Tsukamoto, "Molecular phylogeny and evolution of the freshwater eel, genus Anguilla," Mol Phylogenet Evol, 2001, 20, pp. 450-459.

[2] K. Tsukamoto, "Spawning of eels near a seamount", Nature, 2006, 439, pp. 929.

[3] K. Yamamoto, and K. Yamauchi, "Sexual maturation of Japanese eel and production of eel larvae in the aquarium," Nature, 1974, 251, pp. 220-221.

[4] F. W. Tesch, "The Eel. Biology and management of anguillid eels," Chapman and Hall, London, 1977, pp. 1-434.

[5] R. Zardoya, A. Garrido-Pertierra, and J. M. Bautista, "The complete nucleotide sequence of the mitochondrial DNA genome of the rainbow trout, Oncorhynchus mykiss," J Mol Evol, 1995, 41, pp. 942-951.

[6] H. W. Kang, D. S. Park, S. J. Go, and M. Y. Eun, "Fingerprinting of diverse genomes using PCR with universal rice primers generated from repetitive sequence of Korean weedy rice," Mol Cells, 2002, 13, pp. 281-287.

[7] W. N. Tzeng, Y. T. Wang, and C. H. Wang, "Optimal growth temperature of American eel, Anguilla rostrata (Le Sueur)," J Fish Soc Taiwan, 1998, 25, pp. 111-115.

[8] S. L. Chang, G. H. Kou, and I. C. Liao, "Temperature adaptation of the Japanese eel (Anguilla japonica) in its early stages," Zool Stud, 2004, 43, pp. 571-579.

[9] A. T. Beckenbach, "Rapid mtDNA sequence analysis of fish populations using polymerase chain reaction (PCR)", Can J Fish Aquat Sci, 1991, 48, pp. 95-98.

[10] W. K. Thomas, and A. T. Bechenbach, "Variation in salmoid mitochondrial DNA: Evolutionary constraints and mechanism of substitution," J Mol Evol, 1989, 29, pp. 233-245. 